\title{
Preparation of a nitrogen oil compound fraction by modified gel silica column chromatography
}

Samantha R. C. Silva ${ }^{\dagger}$, Natalia A. P. Moncioso ${ }^{\dagger}$, Cristina M. S. Sad ${ }^{\dagger}$, Cristina L. Tosta ${ }^{\dagger}$, Lindamara M. de Souza ${ }^{\dagger}$, Daniel F. Cipriano ${ }^{\ddagger}$, Wanderson Romão ${ }^{\dagger}$, Jair C. C. Freitas Ricardo M. Kuster†, Eustáquio V. R. de Castro ${ }^{\dagger}$ Paulo R. Filgueiras ${ }^{\dagger *}$. 

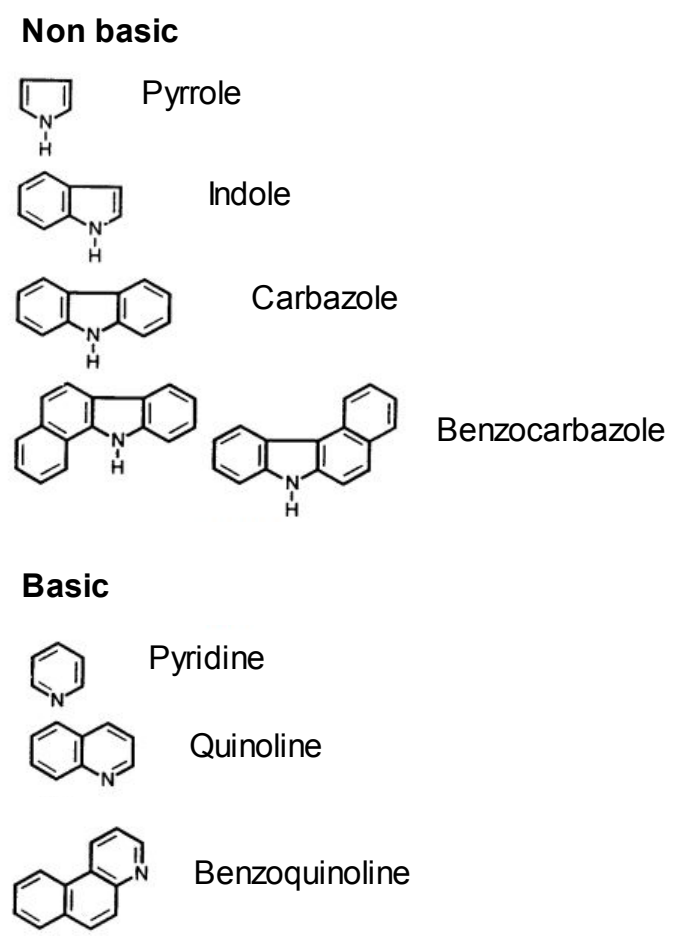

Figure S1. Possible structures of nitrogenous components present in crude oil. 


\section{$\mathrm{NO}[\mathrm{H}]$}
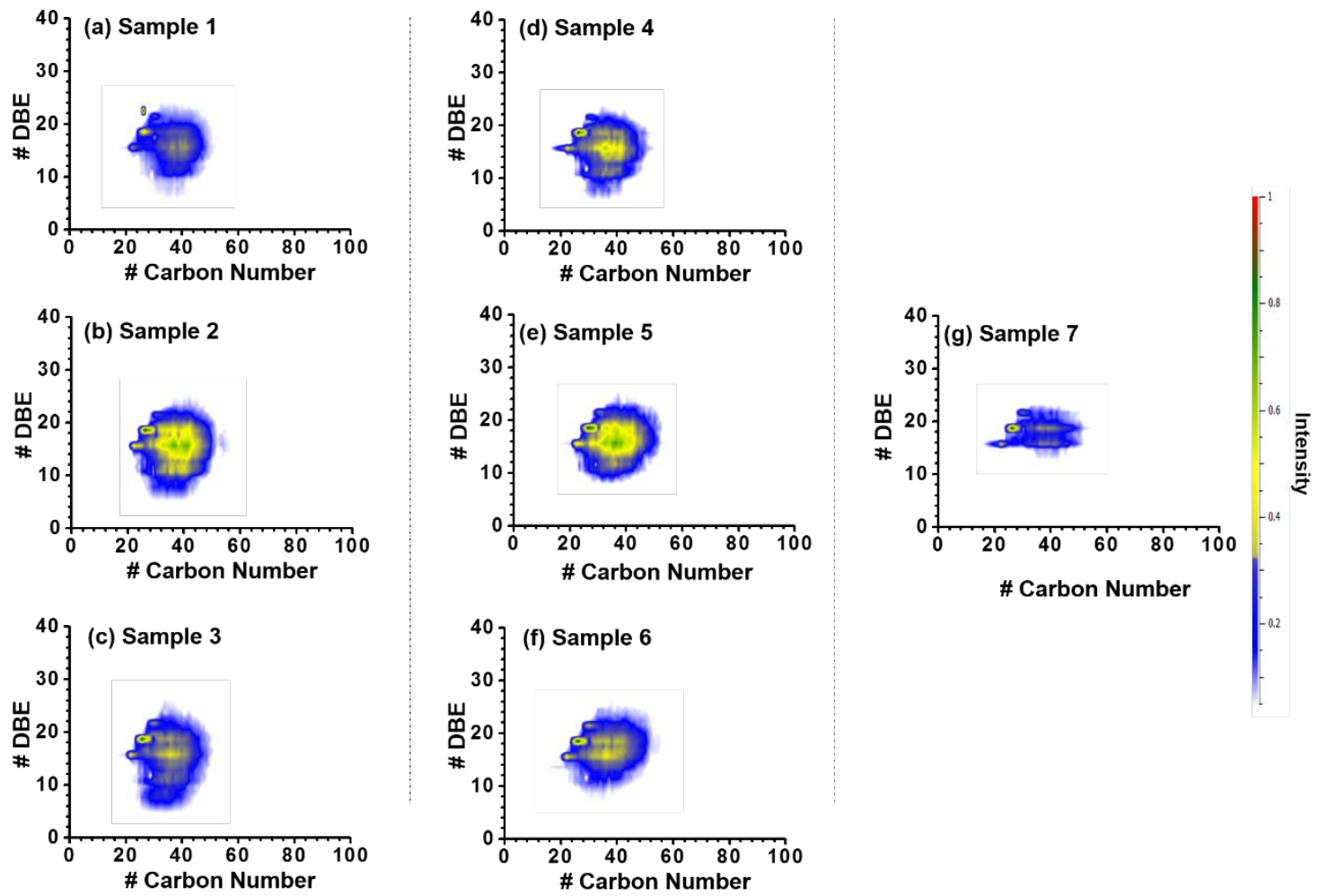

Figure S2. DBE vs. carbon number plots for the $\mathrm{NO}[\mathrm{H}]$ class generated from ESI(-)FT-ICR MS data for sample 1 (a), sample 2 (b), sample 3 (c), sample 4 (d), sample 5 (e), sample 6 (f) and sample 7 (g). 